\title{
Bem-estar pessoal nas organizações e lócus de controle no trabalho
}

\author{
Personal well-being in organizations and work locus of control \\ Bienestar personal en las organizaciones y locus de control laboral
}

\author{
Laila Leite CARNEIRO ${ }^{1}$ \\ Sônia Regina Pereira FERNANDES \\ Universidade Federal da Bahia, Salvador, BA, Brasil
}

Resumo Considerando a lacuna existente na literatura de estudos que focalizem aspectos positivos da relação indivíduo-trabalho-organização, esta investigação se propôs a contribuir com o entendimento sobre o bem-estar do trabalhador. Adotou-se como objetivo geral a análise do poder preditivo do lócus de controle no trabalho sobre o bem-estar pessoal nas organizações, buscando avaliar se o fato de o trabalhador se autoperceber como controlador da situação (internalidade) ou perceber ao outro como detentor desse controle (externalidade) interfere no seu nível de bem-estar. A pesquisa foi de natureza quantitativa e contou com a participação de 200 trabalhadores de duas organizações privadas de Salvador (BA). Os resultados indicaram que a internalidade é capaz de predizer positivamente o bem-estar pessoal nas organizações (tanto a medida global quanto todos os seus indicadores separadamente), destacando-se o seu poder preditivo sobre o indicador "identificação com o trabalho". Já a externalidade apresentou predição negativa e fraca, apenas sobre os indicadores "identificação com a organização" e "suporte ambiental", não apresentando força explicativa sobre a medida global do bem-estar. Finalmente, os resultados deste estudo contribuem para uma melhor compreensão dos processos micro-organizacionais, a partir da identificação de antecedentes que podem facilitar o planejamento de estratégias de intervenção nos contextos de trabalho voltadas para a promoção do bem-estar do trabalhador.

Palavras-chave:

Bem-estar; lócus de controle; trabalho.

\section{Abstract}

Considering the existing gap in the literature on studies that focus on positive aspects of the individual-job-organization relationship, this research aimed to contribute to the understanding of worker well-being. It adopted as its main goal the analysis of the predictive power of work locus of control on personal well-being in the workplace, seeking to assess whether the fact that the worker perceives his/herself as controlling the situation (internality) or perceives the other as the holder of this control (externality), interferes with their level of well-being. The research was quantitative in nature and involved the participation of 200 workers from two private organizations in Salvador (BA). The results indicated that internality is able to positively predict personal well-being in the workplace (both the global measure as well as all its indicators separately), highlighting its predictive power over the indicator "identification with the work". While externality presented a negative and weak predictive power, only over the indicators "identification with the organization" and "environmental support", showing no explanatory power over the global measure of well-being. Finally, the study's findings contribute to a better understanding of micro-organizational processes, based on the identification of antecedents that can facilitate the planning of intervention strategies in work contexts aimed at promoting workers' well-being. Keywords:

Well-being; locus of control; work. 
Teniendo en cuenta la brecha existente en la literatura de los estudios que se centran en los aspectos positivos de la relación organización-trabajo-individuo, esta investigación pretende contribuir a la comprensión del bienestar de los trabajadores. Se ha adoptado como objetivo general el análisis del poder predictivo del locus de control en el trabajo sobre el bienestar personal en las organizaciones, tratando de evaluar si el hecho de que el trabajador se perciba como controlador de una situación (interioridad) o perciba a otros como detentores de este control (externalidad) interfiere en su nivel de bienestar. La investigación fue de naturaleza cuantitativa, y contó con la participación de 200 empleados de dos organizaciones privadas en Salvador (BA). Los resultados indicaron que la interioridad es capaz de predecir positivamente el bienestar personal en las organizaciones (tanto la medida global como cada uno de sus indicadores por separado), destacando su capacidad de predicción sobre el indicador de "identificación con el trabajo.” Por otro lado, la externalidad presentó predicción negativa y débil, sólo sobre los indicadores de "identificación con la organización” y "apoyo ambiental”, sin presentar poder explicativo sobre la medida general de bienestar. Por último, los resultados contribuyen a una mejor comprensión de los processos micro-organizacionales, partiendo de la identificación de antecedentes que pueden facilitar la planificación de estrategias de intervención en contextos de trabajo destinadas a promover el bienestar de los trabajadores.

Palabras-clave:

Bienestar; locus de control; trabajo.

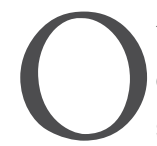
trabalho é uma das formas mais significativas que o indivíduo tem de transformar e transformar-se, deixando, assim, sua marca no mundo. Constatando que é nele que o sujeito passa a maior parte do seu tempo e que é por meio dele que alcança os seus principais objetivos de vida (Álvaro-Estramiana, 2006), torna-se fundamental buscar entender de que forma essa experiência pode ser mais positiva.

Paz, Neiva e Dessen (2012) assinalam que nunca se falou tanto em saúde, bem-estar, direitos, justiça social, trabalho decente e dignidade humana quanto no início do século XXI. A preocupação recente com esses temas dá corpo e solidez ao campo de estudos que se interessa em apreender melhor os benefícios do trabalho para o bem-estar e para a saúde psicológica das pessoas.

Nesse caminho, Mendes e Cruz (2004) defendem que o trabalho pode ser uma fonte de prazer, a depender "das condições nas quais é realizado, da atitude em relação à tarefa e da compatibilidade entre exigências e capacidade do indivíduo" (pp. 41-42). Ao mesmo tempo, Diener e Ryan (2008) sugerem que trabalhadores que se divertem e são mais felizes tendem a receber avaliações de desempenho mais altas dos seus supervisores, a ser mais produtivos, criativos e a apresentar resultados de trabalho de maior qualidade. Além disso, segundo os autores, esses trabalhadores costumam exibir comportamentos de cidadania organizacional com mais frequência, estando mais disponíveis a realizar tarefas que não são necessariamente parte da sua função, como ajudar seus colegas.

No entanto, apesar dos benefícios associados ao bem-estar do trabalhador, ainda são poucos os estudos que visam a avaliar essa temática a partir de uma perspectiva positiva, especialmente na literatura nacional, conforme apontam Paschoal et al. (2013). Embora o interesse científico por essa temática tenha ganhado expressividade apenas nos últimos anos, existem indicações (Ferreira, Souza, \& Silva, 2012) de que a literatura sobre o bem-estar, especialmente do bem-estar no trabalho, vem alcançando avanços a partir da análise de seus antecedentes e consequentes. Nessa linha, Warr (2007) destaca a necessidade de investigar tanto características organizacionais quanto características pessoais que podem influenciar a experiência de bem-estar do trabalhador.

Diante desse cenário, esta investigação propôs-se a contribuir com o entendimento sobre o bem-estar do trabalhador a partir da análise das relações entre dois construtos principais: bem-estar pessoal nas organizações e lócus de controle no trabalho. Questionando qual é o papel do lócus de controle no trabalho sobre o bem-estar pessoal nas organizações, o presente estudo pretendeu aprofundar os conhecimentos concernentes a este construto, verificando se o fato de o trabalhador se perceber como controlador da situação (internalidade) ou perceber ao outro (organização, sorte ou acaso) como detentor desse controle (externalidade) interfere em seu nível de bem-estar.

A compreensão do tipo de relação existente entre essas variáveis pode ajudar a obter um modelo com potencial diagnóstico para prover informações tanto aos pesquisadores quanto aos profissionais de recursos humanos (Dessen \& Paz, 2010). Adicionalmente, esse conhecimento pode facilitar a escolha de intervenções a serem 
adotadas no contexto de trabalho, com ações que facilitem a adaptação de estratégias organizacionais ao perfil dos trabalhadores, contribuindo de maneira mais efetiva para fomentar o bem-estar pessoal nas organizações. Assim, acredita-se que estudos dessa natureza, ao sugerirem um caminho para a manutenção de um ambiente de trabalho mais saudável e propício à realização pessoal, podem ter impactos positivos em diversos setores da vida do indivíduo, assim como influenciar variáveis organizacionais, como o desempenho, a rotatividade e o absenteísmo (Rodríguez-Carvajal, Moreno-Jiménez, Rivas-Hermosilla, Álvarez-Bejarano, \& Vergel, 2010).

Os estudos sobre bem-estar no contexto de trabalho possuem como referência principal o autor Peter Warr, que em 1978 começou a questionar a correspondência entre o bem-estar geral e o bem-estar referente a contextos específicos. A partir dessas reflexões, a literatura da área se desenvolveu, constatando que as relações dos antecedentes do contexto de trabalho são mais fortes com o bem-estar neste contexto do que com o bemestar geral. Em outras palavras, como afirma Dessen, ao utilizar construtos específicos, "a identificação dessas relações contribui mais para a compreensão do fenômeno e para a realização de intervenções” (Dessen, 2010, p. 28).

Diversos construtos já foram formulados com o intuito de entender o bem-estar relacionado ao contexto de trabalho, apresentando diversas visões e nomenclaturas, como: bem-estar ocupacional (Van Horn, Taris, Schaufeli, \& Schreurs, 2004), bem-estar no trabalho (Ferreira, Pacheco, Pinto, Fernandes, \& Silva, 2007; Paschoal, 2008; Siqueira \& Padovam, 2008), felicidade no trabalho (Vasconcelos, 2004), bem-estar pessoal nas organizações (Paz, 2004), entre outros. Em uma revisão sistemática sobre a produção de artigos nacionais acerca dessa temática, Paschoal et al. (2013) destacam que, embora as pesquisas da área resguardem o interesse de avaliar o bem-estar no mundo do trabalho, as concepções e as bases teóricas que sustentam esses construtos variam muito entre si. Em alguns casos, apresentam uma perspectiva hedônica mais voltada para a vivência de prazer, em outros, uma perspectiva que contempla mais os aspectos cognitivos relacionados ao desenvolvimento pessoal, ou, ainda, a combinação de ambas as perspectivas.

Demo e Paschoal (2013) enfatizam que, apesar de existir concordância sobre a importância do bem-estar no trabalho, a ausência de consenso sobre o que define o fenômeno ainda é predominante. Vasconcelos (2004), por exemplo, adota o termo felicidade no trabalho para explorar a satisfação com relação a aspectos do ambiente ocupacional, bem como a frequência e a intensidade de emoções positivas, utilizando como variáveis-chave a satisfação no trabalho, a confiança, a lealdade, a liderança, os valores e o humanismo. Por outro lado, Van Horn et al. (2004) utilizam o conceito de bem-estar ocupacional para se referirem à avaliação positiva de fatores do trabalho, incluindo, além da dimensão afetiva, a profissional, a social, a cognitiva e a psicossomática.

Já Ferreira et al. (2007) definem o bem-estar no trabalho como um construto superordenado que contém uma dimensão cognitiva, representada pela satisfação no trabalho, e uma dimensão afetiva, que engloba os afetos positivos e negativos dirigidos ao trabalho. Paschoal (2008), por sua vez, propõe que o bem-estar no trabalho resulta da prevalência de emoções positivas e da percepção do indivíduo de que, no seu trabalho, expressa e desenvolve seus potenciais e avança no alcance de suas metas de vida. Portanto, esse construto é investigado por meio dos fatores afeto positivo, afeto negativo e realização pessoal no trabalho. Enquanto isso, para Siqueira e Padovam (2008), o bem-estar no trabalho decorre da integração de três fatores: satisfação no trabalho, comprometimento organizacional afetivo e envolvimento com o trabalho.

É interessante destacar que a maior parte dos construtos de bem-estar anteriormente citados tem em comum o fato de avaliarem o bem-estar genericamente em qualquer tipo de trabalho, formal ou informal, remunerado ou não remunerado, realizado de maneira autônoma ou dentro de organizações. Nesse sentido, embora possam ser aplicados a organizações, não são exclusivos a este ambiente.

Diferentemente, o construto de bem-estar pessoal nas organizações, proposto por Paz, em 2004, apresenta uma delimitação mais específica ao contexto de aplicação. Tal construto refere-se à satisfação das necessidades e à realização dos desejos dos indivíduos ao desempenharem seu papel nas organizações. Dessa forma, pressupõe-se uma relação de reciprocidade entre indivíduo e organização, entendendo-se que o bem-estar do indivíduo depende não apenas do quanto seu ambiente lhe provê oportunidades de experiências positivas, mas também do quanto elas são percebidas e aproveitadas.

Desse modo, $\mathrm{Paz}$ (2004) defende que o alcance do bem-estar pessoal nas organizações depende da prática dos direitos e deveres concernentes a ambas as partes. $\mathrm{O}$ empregado tem como dever realizar suas atividades conforme acordado, objetivando alcançar as metas organizacionais que garantam a sobrevivência e o crescimento da empresa, enquanto a organização fica responsável por garantir um ambiente favorável ao alcance de 
tais metas, sem comprometer a saúde do trabalhador, por cujo bem-estar pessoal ela deve se responsabilizar (Dessen \& Paz, 2010). Caracteriza-se, assim, como um fenômeno processual e dinâmico (Paz et al., 2012).

Nesse sentido, a realização dos desejos e a satisfação das necessidades individuais dependem de alguns indicadores que contribuem, ao mesmo tempo, para o bem-estar dos funcionários e para que as organizações se mantenham no mercado com produtividade (Paz, 2004). Inicialmente, o construto de Paz (2004) foi composto por sete indicadores, enumerados com base em entrevistas abertas feitas com trabalhadores de diferentes organizações sobre o que é o bem-estar no contexto de trabalho. Em síntese, os principais fatores identificados foram: (a) valorização do trabalho pelo funcionário, pela organização e pela sociedade; (b) reconhecimento pessoal; (c) autonomia; (d) expectativa de crescimento profissional; (e) suportes material, social e tecnológico; (f) salário justo; e (g) orgulho por fazer parte da organização.

Revisões mais recentes do construto (Dessen, 2010; Dessen \& Paz, 2010) incluíram outras dimensões apresentadas na literatura do bem-estar no contexto de trabalho, alterando também alguns dos indicadores anteriores. A versão mais moderna apresentada por Dessen (2010) é composta por 10 indicadores. Assim, inclui, além dos indicadores já citados, os fatores: relação com a chefia, relação com os colegas e relação com os clientes. Também modifica a composição e a nomenclatura de alguns indicadores: orgulho por fazer parte da organização passa a compor o indicador identificação com a organização; expectativa de crescimento profissional passa a compor o indicador oportunidades de carreira; e reconhecimento pessoal passa a compor o indicador valorização do trabalho. Cabe salientar que esse construto coopera com o campo da psicologia positiva, uma vez que está estruturado por meio de descritores positivos, voltando-se, então, para o desenvolvimento do potencial humano e para a promoção de estratégias que ajudem a tornar as pessoas mais felizes e produtivas, e, ao mesmo tempo, contribui para o funcionamento saudável dos indivíduos, grupos e instituições (Dessen, 2010).

A segunda variável deste estudo, o lócus de controle, possui um histórico de estudos bastante sólido. Este construto foi proposto inicialmente por Julian Rotter, nos anos de 1960, com base na Teoria de Aprendizagem Social. $\mathrm{O}$ autor pretendia investigar a crença das pessoas de que a vida está sob seu próprio controle ou sob a influência do meio externo (Guimarães et al., 2008; Pasquali, Alves, \& Pereira, 1998; Rodrigues \& Pereira, 2007). Tal crença era vista pelo teórico como uma disposição pessoal aprendida pelo indivíduo ao longo de suas experiências cotidianas de controle das contingências de reforço de seu comportamento (Xavier, 2005). Em outras palavras, o lócus de controle é definido por Rotter (1966) como um construto unidimensional que se refere à expectativa quanto às contingências dos próprios comportamentos e eventos, sendo, portanto, formado diretamente pela relação que o indivíduo estabelece consigo mesmo e com seu meio social.

Esse construto é concebido por Rotter (1966) em dois extremos, que formam entre si um contínuo: a internalidade, que seria a tendência de o indivíduo atribuir a causa dos acontecimentos a si mesmo, e a externalidade, que o levaria a atribuir a causa dos acontecimentos a fatores alheios, como o destino, a sorte, a sociedade ou mesmo outras pessoas. Segundo o autor, o controle interno também pode ser entendido como a percepção de que o reforço é contingente à conduta do indivíduo, enquanto o controle externo seria o contrário, caracterizando-se como um reforço percebido como não contingente à alguma ação, explicando-se, portanto, a sua presença a partir de elementos exteriores não previsíveis.

Convém ressaltar que não é necessário que as pessoas exerçam (ou não) realmente controle sobre os eventos relevantes, mas apenas que percebam esse controle, atribuindo-lhe uma fonte específica (Rodrigues \& Pereira, 2007). Seguindo essa linha de raciocínio, Weiner (1983) citado por Rodrigues (2007), ressalta que não são os resultados reais do evento em si que pesam para a tomada de decisão, mas a interpretação deles, que pode ser associada a afetos positivos ou negativos. Logo, de maneira mais genérica, o LC pode ser entendido como expectativas generalizadas sobre a origem das recompensas e dos castigos no mundo (Noriega, Albuquerque, Álvarez, Oliveira, \& Coronado, 2003).

Desde a sua concepção, o lócus de controle vem sendo avaliado por diversas áreas de estudo, através de medidas generalizadas ou específicas a contextos como saúde, casamento, escola ou trabalho (Guimarães et al., 2008, Noriega et al., 2003; Xavier, 2005). Uma das razões pelas quais esse conceito tem se proliferado tanto na literatura é, conforme apontam Pasquali et al. (1998), o seu incontestável poder explicativo. Por isso, os autores defendem que a apreensão do lócus de controle no contexto organizacional e do trabalho pode trazer contribuições para a prática de gestão de pessoas. 
Nesse domínio, encontra-se a concepção de lócus de controle no trabalho proposta por Spector (1988), que o define como uma expectativa generalizada de que recompensas, reforços e resultados no trabalho são controlados pelas próprias ações do indivíduo (internalidade) ou por outras forças (externalidade). Considerando o ambiente organizacional, Spector (1988) destaca que as recompensas e os resultados incluem promoções, circunstâncias favoráveis, aumento salarial e possibilidades de carreira.

Do mesmo modo, autores como Andrisani e Nestel (1976), Spector (1988), Ng, Sorensen e Eby (2006), Wang, Bowling e Eschleman (2010) destacam que o estudo do lócus de controle como uma variável de personalidade pode ser de grande valia para o entendimento dos fenômenos pertinentes à interação indivíduotrabalho-organização. $\mathrm{Ng}$ et al. (2006), especialmente, destacam que a perspectiva de estudo entre lócus de controle e bem-estar é uma das principais formas de avaliar a influência do lócus de controle na atuação do indivíduo no trabalho.

Na psicologia, a produção de conhecimento sobre o bem-estar do indivíduo vem acompanhada da necessidade de compreender suas relações com outras variáveis. A literatura mais recente, por exemplo, converge para a aceitação de que os componentes cognitivos e afetivos do bem-estar se mantêm relativamente consistentes ao longo do tempo e sob diferentes situações, correlacionando-se, assim, com características específicas de personalidade (Giacomoni, 2004). Consoante com essa perspectiva, pesquisas vêm sendo realizadas com o intuito de investigar o bem-estar e suas inter-relações com o lócus de controle (Ahrens \& Ryff, 2006; Elfström \& Kreuter, 2006; García, Ramírez, \& Jariego, 2002; Ng et al., 2006; Rodrigues, 2007; Spector, Cooper, Shancez, O’Driscoll, \& Parks, 2002).

As pesquisas já realizadas que investigaram as relações entre o bem-estar e o lócus de controle foram desenvolvidas tanto em contextos da vida em geral, quanto em contextos específicos, como a aprendizagem ou o trabalho. De modo geral, considerando uma diversidade de contextos, as pesquisas têm apontado resultados consensuais que associam altos níveis de bem-estar com o lócus de controle interno. Em alguns desses estudos (Ahrens \& Ryff, 2006; Elfström \& Kreuter, 2006; García et al., 2002), essa associação configura-se como uma predição na qual o lócus de controle interno (em algumas pesquisas, tratado como percepção de controle pessoal) influencia ou promove o bem-estar. Ainda que em nenhum deles o construto de bem-estar investigado tenha sido o de bem-estar pessoal nas organizações e, em alguma medida, já esteja claro que os diversos construtos de bem-estar podem se comportar de maneiras diferentes em interação com outras variáveis, entende-se que esses estudos podem servir como base para a execução das análises e para a avaliação dos resultados desta pesquisa.

Entre os principais estudos encontrados, destacam-se aqueles que utilizaram como variável central o bem-estar psicológico, como os de García et al. (2002), e Ahrens e Ryff (2006), e o bem-estar emocional ou subjetivo, como os de Elfström e Kreuter (2006) e Rodrigues (2007). Nessas pesquisas, verificou-se associação positiva entre a percepção de controle pessoal (internalidade) e o bem-estar ou seus fatores positivos. Ainda, nas pesquisas de Mohan (2004) e de Rodrigues (2007) foi reportada associação negativa entre o fator externalidade e o bem-estar ou seus fatores positivos.

Além dos estudos já descritos, cabe destacar que $\mathrm{Ng}$ et al. (2006), em uma revisão internacional sobre as relações entre o lócus de controle e o bem-estar (sob a forma de diversos construtos), elencam uma série de pesquisas que apontam o lócus de controle como um preditor do bem-estar do indivíduo, assumindo que o lócus de controle interno gera melhores níveis de bem-estar (p. ex., Bono \& Judge, 2003; Judge \& Bono, 2001; Judge et al., 1998; e Spector et al., 2002 citados por Ng et al., 2006), enquanto o lócus de controle externo associa-se a psicopatologias, como a depressão (Bennassi, Sweeney, \& Dufour, 1988; Phares, 1976; Presson \& Benassi, 1996; e Watson, 1998, citados por Ng et al., 2006). Nessa linha, os autores defendem que é razoável esperar que exista uma relação entre lócus de controle, trabalho e bem-estar ( $\mathrm{Ng}$ et al., 2006).

Sob uma ótica específica do contexto de trabalho, estudos realizados por Spector (1988) e por Spector et al. (2002) também sugerem que a internalidade está associada ao bem-estar positivo tanto na vida em geral quanto no trabalho. Assim, Spector (1988) descreve que trabalhadores com orientação de lócus de controle de internalidade, também chamados de internos, tendem a ser mais satisfeitos com seus empregos do que trabalhadores com orientação de lócus de controle de externalidade, também chamados de externos, além de avaliarem seus supervisores de forma mais positiva, apresentarem menos estresse, aproveitarem por mais tempo o ambiente de trabalho e perceberem mais autonomia e controle. 
A revisão dos estudos empíricos apresentados reforça a tendência geral em assumir que existem relações significativas entre bem-estar e lócus de controle. Em algumas das pesquisas realizadas (Ahrens \& Ryff, 2006; Elfström \& Kreuter, 2006; García et al., 2002), têm-se apontado de forma mais clara que essa é uma relação de predição, na qual o lócus de controle assume um papel de antecedente para o bem-estar. No entanto, é importante que novos estudos sejam realizados no intuito de corroborar e dar mais subsídios que sustentem essa visão, especialmente considerando como essas relações se configuram no contexto de trabalho. Nesse sentido, este estudo teve como objetivo analisar o poder preditivo do lócus de controle no trabalho sobre os níveis de bem-estar pessoal nas organizações.

Embora as relações entre os construtos bem-estar pessoal nas organizações e lócus de controle no trabalho ainda não tenham sido avaliadas de forma específica, existem indicações na literatura quanto a pesquisas realizadas que adotaram focos diferentes, como o bem-estar subjetivo e o bem-estar psicológico, que, considerando sua aproximação com o construto bem-estar pessoal nas organizações, permitiram levantar algumas hipóteses. Nesse sentido, com base nos resultados apontados pelos estudos de García et al. (2002), Spector et al. (2002), Ahrens e Ryff (2006), Elfström e Kreuter (2006) e Rodrigues (2007), bem como na revisão de literatura de Ng et al. (2006), elaborou-se a primeira hipótese de pesquisa.

H1: O lócus de controle interno no trabalho está positivamente associado à medida global de bem-estar pessoal nas organizações e a seus indicadores separadamente.

Embora poucos estudos relatem a relação entre a externalidade e o bem-estar, as pesquisas realizadas por Mohan (2004) e Rodrigues (2007) permitiram subsidiar a segunda hipótese de pesquisa.

H2: O lócus de controle externo no trabalho está negativamente associado à medida global de bem-estar pessoal nas organizações e a seus indicadores separadamente.

Finalmente, a avaliação geral dos resultados dos estudos revisados na literatura, que mostraram um descompasso entre o impacto preditivo do fator internalidade e do fator externalidade, embasou a construção da terceira hipótese de pesquisa.

H3: O fator internalidade do lócus de controle no trabalho apresentará maior poder explicativo sobre os indicadores de bem-estar pessoal nas organizações do que o fator externalidade.

\section{MÉTODO}

\section{Participantes}

O critério de elegibilidade dos profissionais participantes desta pesquisa foi a existência de um vínculo empregatício formal com a organização em que trabalhavam de, no mínimo, três meses, visto que, de acordo com o Decreto de Lei n 229 de 1967 pertinente à Consolidação das Leis do Trabalho (CLT), esse constitui o período de experiência. Compreende-se, assim, que nesse período o trabalhador está se adaptando à empresa e sua permanência ainda é instável. Entende-se que essas condições servem como controle, posto que, dada a proliferação de tipos de contratos existentes hoje em dia, variáveis como a instabilidade do vínculo empregatício podem influenciar tanto os níveis de bem-estar do trabalhador como a sua percepção de lócus de controle. Já a escolha das organizações foi baseada nos seguintes critérios: (a) porte médio ou grande para facilitar o cumprimento de um número significativo de participantes, (b) número reduzido de organizações para melhor controlar a variabilidade contextual de trabalho da amostra e (c) facilidade de acesso.

Desse modo, a amostra foi composta por conveniência, formada por 200 trabalhadores de duas organizações privadas: uma no setor de serviços ( $n=98,49 \%$ dos participantes) e outra no setor de varejo ( $n=102,51 \%$ dos participantes). De modo geral, os profissionais estavam distribuídos em seis áreas principais de atuação/ ocupação, definidas nas categorias: administrativa $(52,3 \%)$, vendas $(26,1 \%)$, motoristas $(6,0 \%)$, tecnologia da informação (6,0\%), ajudantes/serviços gerais $(8,0 \%)$ e outros (1,5\%). Quanto à remuneração, a maioria $(63,6 \%)$ recebia até dois salários mínimos.

A amostra apresentou equilíbrio quanto à distribuição de homens $(54,0 \%)$ e mulheres (46,0\%). Os profissionais situaram-se, em sua maioria (87,6\%), na faixa etária entre 18 e 35 anos. Identificou-se, ainda, que, apesar de os profissionais realizarem atividades predominantemente operacionais, 50,5\% deles apresentavam nível de escolaridade superior incompleto ou completo. 


\section{Instrumentos}

Como instrumento de pesquisa, foi utilizado um questionário divido em três partes: questionário sociodemográfico, escala de indicadores de bem-estar pessoal nas organizações e escala de lócus de controle no trabalho.

1. Questionário sociodemográfico - Levantamento de variáveis pessoais (sexo, idade, estado civil e escolaridade) e ocupacionais (profissão, tempo de carreira, tempo na empresa, remuneração e carga horária de trabalho).

2. Escala de indicadores de bem-estar pessoal nas organizações - A escala foi validada por Dessen e Paz (2010) e adaptada por Dessen (2010), é composta por 49 itens distribuídos em 10 fatores: salário (6 itens, $\alpha=0,91$ ), relação com a chefia (6 itens, $\alpha=0,93$ ), relação com colegas (6 itens, $\alpha=0,87$ ), relação com clientes ( 3 itens, $\alpha=0,76$ ), autonomia ( 4 itens, $\alpha=0,80$ ), identificação com a organização ( 6 itens, $\alpha=0,90$ ), identificação com o trabalho ( 6 itens, $\alpha=0,87$ ), oportunidades de crescimento ( 4 itens, $\alpha=0,82$ ), suporte ambiental ( 4 itens, $\alpha=0,79$ ) e valorização do trabalho ( 4 itens, $\alpha=0,75$ ). Os itens deveriam ser avaliados com base em uma escala de frequência de 5 pontos, sendo: 0-Nunca, 1-Raramente, 2-Às vezes, 3-Frequentemente, 4-Sempre.

3. Escala de lócus de controle no trabalho - A escala de Spector (1988), validada para o Brasil por Bastos (1991) e adaptada por Xavier (2005), é composta por 16 itens distribuídos em dois fatores: internalidade ( 8 itens, $\alpha=0,62$ ) e externalidade ( 8 itens, $\alpha=0,78$ ). Os itens deveriam ser avaliados com base em opções de respostas em 5 níveis: 1-Discordo totalmente; 2-Discordo parcialmente; 3-Não concordo, nem discordo; 4-Concordo parcialmente; 5-Concordo totalmente.

\section{Procedimentos de coleta de dados}

A coleta de dados foi realizada no período de dezembro de 2012 a março de 2013. Os instrumentos foram disponibilizados apenas na versão impressa, sendo administrados no local de trabalho, de forma individual ou coletiva, para aqueles trabalhadores que se dispuseram a participar voluntariamente da pesquisa. Para atender às recomendações do Comitê Nacional de Ética na Pesquisa (CONEP), foi anexado junto ao instrumento de coleta um termo de consentimento livre e esclarecido, no qual estavam dispostas informações sobre a importância acadêmica da pesquisa, bem como da garantia de anonimato e do caráter voluntário do preenchimento das escalas.

\section{Procedimentos de análise de dados}

A análise dos dados foi viabilizada através do software SPSS 17.0 (Software Package for Social Sciences). Primeiramente, foram realizadas análises estatísticas exploratórias para identificar e corrigir problemas de digitação, dados omissos (missings) e casos extremos (outliers). As avaliações subsequentes através de testes de skewness, kurtosis e do teste Kolmogorov-Smirnov demonstraram adequação da amostra em termos de normalidade.

Embora as escalas utilizadas já tivessem sido validadas para a realidade brasileira, considerou-se necessário realizar a análise fatorial novamente, na tentativa de garantir que os instrumentos estivessem adequados à amostra específica de trabalhadores participantes deste estudo. Além disso, no caso da escala de indicadores de bem-estar pessoal nas organizações, por se tratar de um instrumento recém-construído, as autoras que o validaram (Dessen \& Paz, 2010) incentivam que sejam feitos novos estudos voltados à melhoria e à otimização do instrumento. Sobre a escala de lócus de controle no trabalho, levou-se em consideração o fato de que, apesar de amplamente utilizada em pesquisas, ela apresenta índices psicométricos que ainda não se mostram ideais (Bastos, 1991; Xavier, 2005), especialmente quanto ao fator internalidade, o que também sugere indicações de melhorias.

Foi adotado o método de análise de componentes principais (ACP), com rotação oblíqua (promax), que pressupõe que existe correlação entre os fatores estudados (Field, 2009). Ressalta-se que a retenção de fatores se baseou em uma avaliação que considerou tanto a disposição do screeplot quanto o critério de autovalor (eigenvalue) maior que 1,0. Já a carga fatorial mínima considerada para retenção dos itens nos fatores foi de 0,4, conforme indicado por Stevens (1992, citado por Field, 2009). Visando a encontrar uma solução que correspondesse melhor aos construtos, em termos teóricos e psicométricos, foram utilizados dois critérios: (a) 
foram excluídos itens que não apresentaram carga fatorial em nenhum dos fatores e (b) foram excluídos itens que se acoplaram a fatores nos quais não havia correspondência teórica direta.

Para a escala de indicadores de bem-estar pessoal nas organizações, a solução mais adequada foi composta por 44 itens, distribuídos em 9 fatores que, juntos, explicaram 71,37\% da variação do construto, com KMO de 0,91 . Destes fatores, 8 corresponderam à proposta original (salário, $\alpha=0,92$; relação com a chefia, $\alpha=0,94$; identificação com a organização, $\alpha=0,91$; relação com os colegas de trabalho, $\alpha=0,87$; identificação com o trabalho, $\alpha=0,85$; suporte ambiental, $\alpha=0,73$; relação com os clientes, $\alpha=0,75$ e valorização do trabalho, $\alpha=0,71$ ). Porém, os fatores originalmente nomeados por autonomia e oportunidades de crescimento na organização condensaram-se em um único fator, nomeado como crescimento/autonomia $(\alpha=0,90)$.

Para a escala de lócus de controle no trabalho, encontrou-se como mais adequada a solução de 14 itens distribuídos em dois fatores, sendo um a externalidade $(\alpha=0,81)$ e outro a internalidade $(\alpha=0,66)$, responsáveis por 42,34\% da variância explicada, com KMO de 0,77. Nesse caso, assinala-se que os índices psicométricos encontrados para essa escala foram melhores do que os apresentados em estudos anteriores (Bastos, 1991; Xavier, 2005).

Por fim, foram realizadas as análises de regressão linear múltipla entre os construtos centrais do estudo. Utilizou-se o método de entrada stepwise, pois, apesar da existência de hipóteses que pressupõem o relacionamento entre o bem-estar e o lócus de controle, ressalta-se que os estudos que embasaram tais hipóteses empregaram construtos teóricos próximos dos aqui postos em avaliação, porém, não iguais. Assim, esse método mostrou-se adequado, uma vez que a regressão stepwise é mais utilizada em estudos exploratórios, para os quais não existe forte literatura teórica disponível (Field, 2009). Consideraram-se como variáveis-critério tanto a medida global de bem-estar pessoal nas organizações (BEPO) quanto os seus indicadores separadamente e, como variáveis preditoras, o lócus de controle interno (LCI) e o lócus de controle externo (LCE).

\section{RESULTADOS}

$\mathrm{Na}$ análise de regressão que utilizou a medida global de bem-estar pessoal nas organizações como variável critério, verificou-se que a variável LCE foi excluída do modelo, pois não demonstrou poder significativo de predição sobre o BEPO, contrariando parcialmente o previsto pela segunda hipótese de pesquisa (H2). Já o LCI apresentou associação moderada com a variável $\left(R^{2}=0,11, \beta=0,34, p<0,01\right)$, explicando em torno de $11 \%$ da variação do bem-estar pessoal nas organizações, o que dá suporte à primeira hipótese de pesquisa (H1), como pode ser constatado na Tabela 1.

TABELA 1. Regressão linear com a medida global de bem-estar pessoal nas organizações

\begin{tabular}{|c|c|c|c|c|}
\hline \multicolumn{2}{|c|}{ Resumo do modelo } & $\boldsymbol{R}$ & $R^{2}$ & $\Delta \boldsymbol{R}^{2}$ \\
\hline \multirow{2}{*}{ Variável critério } & \multirow{2}{*}{ Variável antecedente } & 0,34 & 0,12 & 0,11 \\
\hline & & $B$ & $\beta$ & $T$ \\
\hline BEPO & $\mathrm{LCl}$ & 0,33 & $0,34^{\star *}$ & 5,04 \\
\hline
\end{tabular}

Nota. BEPO corresponde a bem-estar pessoal nas organizações; LCl corresponde a lócus de controle interno no trabalho; ${ }^{* \star}$ p< $0,01$.

A Tabela 2 apresenta os resultados das análises de regressão realizadas com os indicadores de bem-estar pessoal nas organizações. 
TABELA 2. Regressão linear com os indicadores de bem-estar pessoal nas organizações

\begin{tabular}{|c|c|c|c|c|}
\hline \multicolumn{2}{|c|}{ Resumo do modelo } & $R$ & $R^{2}$ & $\Delta R^{2}$ \\
\hline \multirow{2}{*}{ Variável critério } & \multirow{2}{*}{ Variável antecedente } & 0,25 & 0,06 & 0,06 \\
\hline & & $B$ & $\beta$ & $T$ \\
\hline Salário & $\mathrm{LCl}$ & 0,37 & $0,25^{\star \star}$ & 3,63 \\
\hline \multicolumn{2}{|c|}{ Resumo do modelo } & $R$ & $R^{2}$ & $\Delta R^{2}$ \\
\hline & & 0,23 & 0,06 & 0,05 \\
\hline Variável critério & Variável antecedente & $B$ & $\beta$ & $T$ \\
\hline Relação com os colegas & $\mathrm{LCl}$ & 0,27 & $0,23^{\star *}$ & 3,31 \\
\hline \multicolumn{2}{|c|}{ Resumo do modelo } & $R$ & $R^{2}$ & $\Delta R^{2}$ \\
\hline & & 0,17 & 0,03 & 0,02 \\
\hline Variável critério & Variável antecedente & $B$ & $\beta$ & $T$ \\
\hline Relação com os clientes & $\mathrm{LCl}$ & 0,22 & $0,17^{\star}$ & 2,392 \\
\hline \multicolumn{2}{|c|}{ Resumo do modelo } & $R$ & $R^{2}$ & $\Delta R^{2}$ \\
\hline & & 0,26 & 0,07 & 0,06 \\
\hline & & 0,31 & 0,10 & 0,09 \\
\hline Variável critério & Variável antecedente & $B$ & $\beta$ & $T$ \\
\hline \multirow{2}{*}{ Identificação com a organização } & $\mathrm{LCl}$ & 0,30 & $0,25^{\star *}$ & 3,69 \\
\hline & LCE & $-0,16$ & $-0,17^{*}$ & $-2,48$ \\
\hline \multirow{2}{*}{\multicolumn{2}{|c|}{ Resumo do modelo }} & $R$ & $R^{2}$ & $\Delta R^{2}$ \\
\hline & & 0,17 & 0,03 & 0,02 \\
\hline Variável critério & Variável antecedente & $B$ & $\beta$ & $T$ \\
\hline Relação com a chefia & $\mathrm{LCl}$ & 0,26 & $0,17^{\star}$ & 2,37 \\
\hline \multirow{2}{*}{\multicolumn{2}{|c|}{ Resumo do modelo }} & $R$ & $R^{2}$ & $\Delta R^{2}$ \\
\hline & & 0,27 & 0,07 & 0,07 \\
\hline Variável critério & Variável antecedente & $B$ & $\beta$ & $T$ \\
\hline Crescimento/autonomia & $\mathrm{LCl}$ & 0,38 & $0,27^{\star \star}$ & 3,81 \\
\hline \multicolumn{2}{|c|}{ Resumo do modelo } & $R$ & $R^{2}$ & $\Delta R^{2}$ \\
\hline & & 0,43 & 0,19 & 0,18 \\
\hline Variável critério & Variável antecedente & $B$ & $\beta$ & $T$ \\
\hline Identificação com o trabalho & $\mathrm{LCl}$ & 0,58 & $0,43^{\star *}$ & 6,65 \\
\hline \multicolumn{2}{|c|}{ Resumo do modelo } & $R$ & $R^{2}$ & $\Delta R^{2}$ \\
\hline & & 0,17 & 0,03 & 0,02 \\
\hline & & 0,22 & 0,05 & 0,04 \\
\hline Variável critério & Variável antecedente & $B$ & $\beta$ & $T$ \\
\hline \multirow[t]{2}{*}{ Suporte ambiental } & $\mathrm{LCl}$ & 0,25 & $0,17^{\star}$ & 2,39 \\
\hline & LCE & $-0,17$ & $-0,14^{*}$ & $-2,00$ \\
\hline \multicolumn{2}{|c|}{ Resumo do modelo } & $R$ & $R^{2}$ & $\Delta R^{2}$ \\
\hline & & 0,21 & 0,04 & 0,04 \\
\hline Variável critério & Variável antecedente & $B$ & $\beta$ & $T$ \\
\hline Valorização do trabalho & $\mathrm{LCl}$ & 0,26 & $0,21^{*}$ & 2,96 \\
\hline
\end{tabular}

Nota. BEPO corresponde a bem-estar pessoal nas organizações; LCE corresponde a lócus de controle externo no trabalho; LCI corresponde a lócus de controle interno no trabalho; ${ }^{* *} p<0,01,{ }^{*} p<0,05$.

Ao avaliar os modelos de regressão separadamente, identificou-se, conforme previsto na primeira hipótese de pesquisa (H1), que o LCI se apresentou como variável antecedente positiva de todos os indicadores de bem-estar pessoal nas organizações. Contudo, a força da associação entre o LCI e os indicadores de BEPO não foi uniforme. Embora sua explicação tenha sido mais presente no indicador identificação com o trabalho $\left(\Delta R^{2}=0,18, \beta=0,43, p<0,01\right)$, constatou-se que a internalidade foi capaz de explicar a variação dos demais indicadores do bem-estar pessoal nas organizações entre 2 e $9 \%$. Nesse sentido, essas associações podem ser classificadas como: (a) fracas com os indicadores suporte ambiental $(\beta=0,17)$, relação com os clientes $(\beta=0,17)$ e relação com a chefia $(\beta=0,17)$; (b) moderadas com os indicadores valorização do trabalho $(\beta=0,21)$, relação com os colegas $(\beta=0,23)$, salário $(\beta=0,25)$, identificação com a organização $(\beta=0,25)$ e crescimento/autonomia $(\beta=0,27)$; e (c) forte com o indicador identificação com o trabalho $(\beta=0,43)$.

Por outro lado, a avaliação do poder preditivo do LCE corroborou parcialmente o previsto pela $\mathrm{H} 2$, que pressupunha uma associação negativa entre este fator e os indicadores de BEPO. O LCE mostrou ser um antecedente negativo de apenas dois dos indicadores de bem-estar pessoal nas organizações, podendo-se classificar sua associação com ambos os indicadores de identificação com a organização $(\beta=-0,17)$ e de suporte ambiental $(\beta=-0,14)$ como fraca. 
Por fim, comparando a força preditiva dos fatores LCI e LCE, foi corroborada a terceira hipótese de pesquisa (H3), a qual previa que o fator internalidade do lócus de controle no trabalho (LCI) apresentaria maior poder explicativo sobre os indicadores de bem-estar pessoal nas organizações do que o fator externalidade (LCE). Na Figura 1, pode-se visualizar a síntese das análises de regressão realizadas, descritas em termos de direção e força preditiva dos fatores de lócus de controle no trabalho sobre os indicadores de bem-estar pessoal nas organizações.

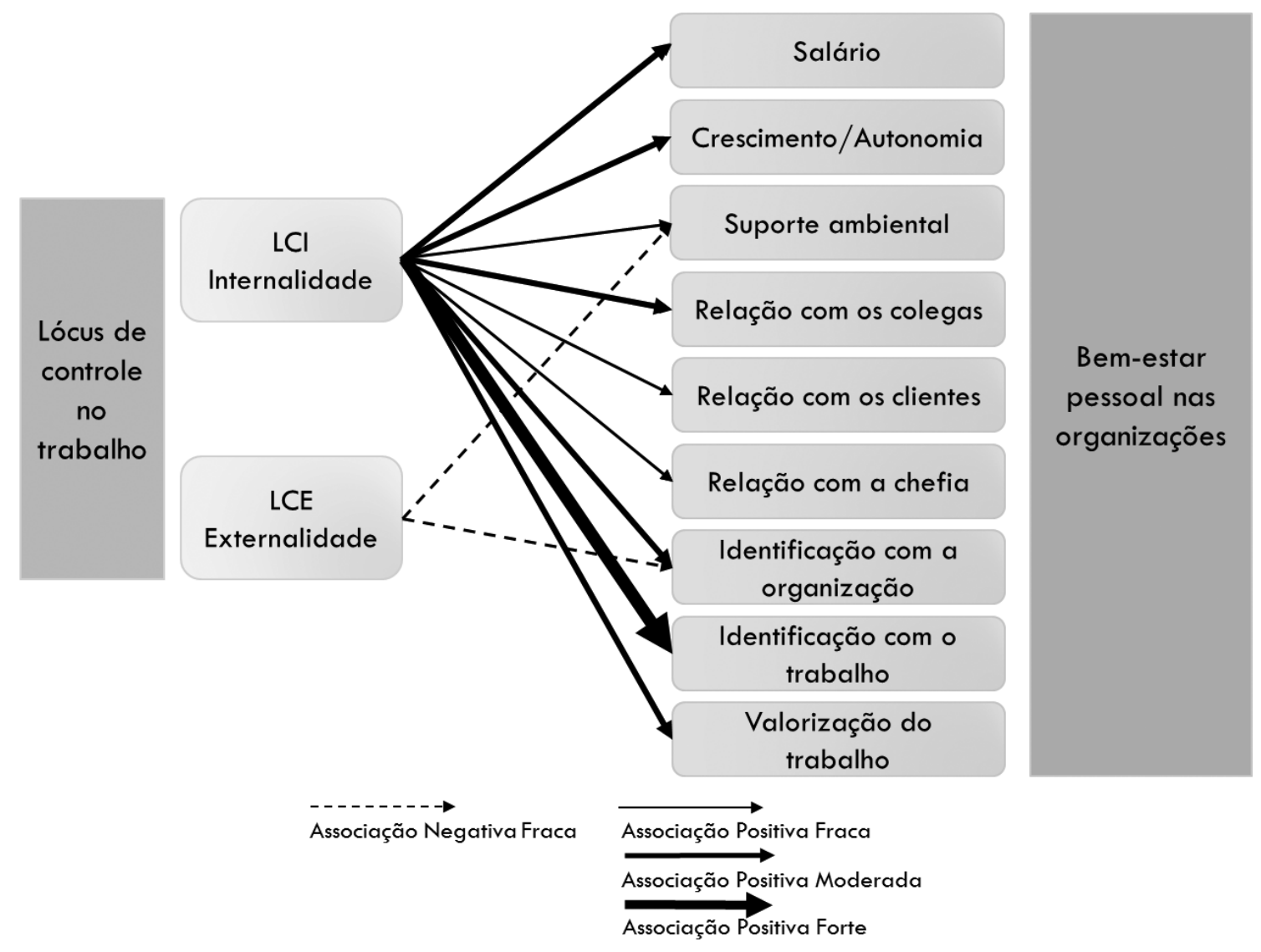

FIGURA 1. Síntese da análise de regressão com os indicadores de bem-estar pessoal nas organizações.

\section{DISCUSSÃO}

A relação de predição do LCI sobre o bem-estar encontrada nesta pesquisa já havia sido apontada em estudos realizados em contextos mais gerais e com outras medidas de bem-estar e lócus de controle, como as de García et al. (2002) e Elfström e Kreuter (2006). Salienta-se, ainda, que alguns autores (Ng et al., 2006; Spector et al., 2002) já apontavam que essa associação poderia acontecer também quando o contexto específico de trabalho fosse avaliado. Nesse sentido, destaca-se a importância de confirmar, em um estudo dedicado ao contexto de trabalho, que o LCI é capaz de predizer parte da variação BEPO, ainda que esse efeito seja moderado.

Nos modelos testados, o LCI permaneceu como preditor significativo positivo de todos os indicadores, bem como da medida global de BEPO. Em contrapartida, o LCE foi excluído da maior parte dos modelos, demonstrando predição negativa e fraca apenas sobre os indicadores suporte ambiental e identificação com a organização. Além disso, cabe destacar que, enquanto o efeito do LCI sobre os indicadores foi positivo, o do LCE foi negativo.

Em outras palavras, os resultados indicam que quanto maior a orientação para a internalidade, mais os trabalhadores: se identificam com a atividade que realizam; percebem oportunidades de crescer e se expressar em seu trabalho; mostram-se orgulhosos e identificados com a organização em que trabalham; acreditam que o seu salário é justo; estabelecem relacionamentos saudáveis com os colegas; sentem que o seu trabalho é valorizado; gostam do relacionamento que mantêm com os clientes e com a chefia; e percebem a existência de um ambiente físico seguro e favorável para a sua saúde; respectivamente. Por outro lado, quanto maior a 
orientação para a externalidade, menos os trabalhadores confiam e admiram a organização em que trabalham, além de perceberem menos a existência de um ambiente físico seguro e favorável para a sua saúde.

É importante salientar que a análise do BEPO a partir dos seus indicadores é relevante, pois pode trazer contribuições não apenas para compreender o que afeta os trabalhadores, mas também para orientar intervenções que aumentem o seu nível de bem-estar (Dessen \& Paz, 2010). Considerando a força da predição encontrada entre os padrões de lócus de controle e os indicadores de BEPO, pontua-se que as principais relações estabelecidas são entre o LCI e a identificação com o trabalho e o crescimento/autonomia.

Não foram encontradas referências na literatura que versem sobre a associação do LCI com a identificação com o trabalho. Entretanto, pode-se analisar que, à medida que o indivíduo se autopercebe como responsável pelos eventos que ocorrem em seu trabalho, pode ter mais segurança de estar no local em que deseja, realizando tarefas variadas e interessantes, que façam valer seus talentos e habilidades. Desse modo, o trabalhador mostra-se mais identificado com aquele trabalho que acredita ser fruto da sua própria escolha, percebendo, portanto, mais possibilidades de desenvolver o seu potencial e, apresentando, assim, maior nível de bem-estar.

No tocante ao indicador crescimento/autonomia, Spector (1988) já havia descrito que os internos possuíam maior tendência de perceberem autonomia. Menciona-se, ainda, que Xavier (2005) já havia relatado que a internalidade estava positivamente relacionada com a oportunidade de aprimorar habilidades no trabalho. Em termos de predição, destaca-se apenas o estudo de Ahrens e Ryff (2006), que reportam que altos níveis de controle predizem altos níveis de autonomia. Logo, os dados apresentados apoiam que, quando há orientação para a internalidade, o trabalhador tende a perceber com mais frequência as possibilidades de ascender e expressar-se no emprego, uma vez que avalia as oportunidades como resultantes de um empenho pessoal, ainda que, objetivamente, este fator seja bastante influenciado pelas condições organizacionais.

Em síntese, depreende-se que os dados discutidos na primeira hipótese (H1) desta pesquisa foi corroborada, tendo em vista que o LCI no trabalho apresentou associação positiva tanto com a medida global de BEPO quanto com todos os seus indicadores separadamente. Já a segunda hipótese (H2) foi parcialmente corroborada, pois o LCE no trabalho apresentou associação negativa apenas com dois indicadores de BEPO, não demonstrando qualquer associação com a medida global de BEPO ou com os demais indicadores. Por fim, a terceira hipótese (H3) foi corroborada, uma vez que o fator internalidade apresentou maior poder explicativo sobre os indicadores de BEPO do que o fator externalidade. O LCE permaneceu no modelo explicativo apenas dos indicadores identificação com a organização e suporte ambiental, destacando-se que, mesmo nesses modelos, a força de explicação do LCI foi superior à do LCE.

Acredita-se que a tentativa de entender a relação entre diferentes indicadores de BEPO com os padrões de lócus de controle no trabalho possibilita uma nova perspectiva de análise teórica, bem como novas contribuições práticas. Pode-se citar como exemplo, que, se em certa equipe ou organização existe uma crença comum de que determinado indicador de bem-estar está sob controle da organização (outros), este fator se torna mais passível de intervenção por parte da gestão organizacional. Por outro lado, caso um indicador seja consensualmente percebido sob controle do próprio trabalhador, a organização pode adotar estratégias que favoreçam o desenvolvimento individual das competências que, efetivamente, o concretizem. Assim, tendo-se clareza sobre os pontos potenciais de intervenção, torna-se mais fácil providenciar mudanças que comunguem do objetivo de melhorar o bem-estar do trabalhador.

No entanto, embora o lócus de controle tenha apresentado poder de predição entre 2 e $18 \%$ sobre a variação dos indicadores de bem-estar pessoal nas organizações, é preciso considerar que outras variáveis individuais, além de variáveis organizacionais, devem ser testadas a fim de construir um modelo que melhor explique esse construto. Pesquisas relatadas por Dessen (2010), Dessen e Paz (2010), Paz, Gosendo, Dessen e Mourão (2009) e Souza (2012) já assinalaram que as seguintes variáveis podem vir a compor esse modelo: configurações de poder, justiça organizacional, valores organizacionais, percepção da cultura, ações de qualidade de vida no trabalho e de qualidade de vida do trabalhador, traços de personalidade (big five) e perfil pessoal. Portanto, para que análises mais consistentes sejam realizadas, é importante que essas investigações sejam replicadas em diferentes amostras e contextos, trazendo mais conhecimento sobre os antecedentes dos indicadores de BEPO.

Considera-se que este estudo contribui com a subárea de conhecimento de bem-estar relacionado ao trabalho ao analisar, em um contexto específico de trabalho, uma associação que já havia sido identificada em um cenário mais amplo entre lócus de controle e bem-estar. Os dados sugeriram que o fator internalidade do lócus de controle no trabalho é um preditor positivo da medida global de BEPO, bem como dos seus indicadores 
separadamente, em especial do indicador identificação com o trabalho. Já o fator externalidade do lócus de controle no trabalho demonstrou predizer de forma negativa os indicadores identificação com a organização e suporte ambiental, não apresentando poder explicativo sobre a medida global do bem-estar. Como essa associação foi bastante fraca, é recomendável que outros estudos sejam realizados para aprofundar a questão. Diante desses resultados, recomenda-se que o lócus de controle no trabalho continue sendo estudado em associação com o bem-estar pessoal nas organizações, a fim de identificar os antecedentes que influenciam a percepção dos trabalhadores quanto a essa variável, permitindo que novas práticas de incentivo e promoção do bem-estar do trabalhador sejam pensadas.

Esta pesquisa possui limitações que precisam ser consideradas. Destaca-se, em primeiro lugar, que a amostra participante do estudo foi eleita por conveniência, uma vez que foram contemplados para a coleta de dados os trabalhadores das primeiras empresas privadas que viabilizaram o acesso para a pesquisa. Assim, os resultados aqui encontrados não podem ser generalizáveis à população de trabalhadores. É necessário ressaltar também que, em termos de instrumentos de pesquisa, o índice de confiabilidade do fator internalidade da escala de lócus de controle no trabalho, mesmo após os ajustes da análise fatorial, ainda não se mostrou dentro dos padrões ideais, o que sinaliza a necessidade de investir em estudos futuros que visem melhorar o rigor psicométrico dessa escala.

Além disso, ressalta-se que esta pesquisa se focou na análise de características individuais, não incorporando em seu modelo características organizacionais potencialmente relevantes para a explicação do bem-estar pessoal nas organizações, cuja avaliação, como se subentende a partir do próprio nome, depende diretamente do contexto organizacional onde ele é mensurado. Dessa forma, as características organizacionais e as políticas de gestão de pessoas são variáveis que merecem atenção, contudo, elas não foram mapeadas aqui por motivos de restrição no contato com as empresas participantes. Algumas dessas características puderam ser acessadas pelo entendimento dos ramos de atuação das empresas, que comportam atividades de trabalho predominantemente operacionais. Todavia, acredita-se que o conhecimento mais detalhado do cenário organizacional é importante para a construção de um entendimento mais complexo do fenômeno de pesquisa.

É importante lembrar que as limitações citadas não invalidam os resultados e discussões suscitados. Entretanto, cabem esforços no sentido de preveni-las na realização de estudos futuros, que podem ser desenvolvidos em diferentes vertentes a fim de intensificar o conhecimento sobre a temática de bem-estar pessoal nas organizações e suas relações com o lócus de controle no trabalho.

Aponta-se, também, que o interesse recente dos estudos psicológicos sobre o bem-estar associado ao contexto de trabalho veio acompanhado de iniciativas diversas para sua conceituação e mensuração. Portanto, para as pesquisas que se dedicam à construção e à discussão teórica dos conceitos de bem-estar, considera-se interessante sugerir a realização de estudos posteriores que se dediquem à comparação entre os diferentes construtos de bem-estar, a fim de melhor compreender o poder explicativo de cada um e, assim, concentrar esforços perante àqueles que apresentem maior possibilidade de contribuir para o desenvolvimento da teoria e da prática. Finalmente, espera-se que os estudos futuros possam continuar fomentando a perspectiva positiva do bem-estar do trabalhador, motivando a construção de espaços de trabalho que favoreçam a autorrealização do profissional e uma troca mais satisfatória entre indivíduo, trabalho e organização.

\section{REFERÊNCIAS}

Ahrens, C. J. C., \& Ryff, C. D. (2006). Multiple roles and well-being: Sociodemographic and psychological moderators. Sex Roles, 55(11-12), 801-815. doi:10.1007/s11199-006-9134-8

Álvaro-Estramiana, J. A. (2006). Las funciones del trabajo. In: A. L. Garrido (Org.), Sociopsicología del trabajo (pp. 32-40). Barcelona: Pujol e Amado.

Andrisani, P. J., \& Nestel, G. (1976). Internal-external control as contributor to and outcome of work experience. Journal of Applied Psychology, 61(2), 156-165. doi:10.1037/0021-9010.61.2.156

Bastos, A. V. B. (1991). Validação da escala de locus de controle no trabalho (Spector, 1988). PSICO, 22(2), 133-154.

Decreto de Lei nº 229 de 28 de fevereiro de 1967. (1967, 28 de fevereiro). Consolidação das Leis do Trabalho. Diário Oficial da União, Seção 1. Recuperado de http://www.planalto.gov.br/ccivil_03/decreto-lei/Del0229.htm\#art443§2

Demo, G., \& Paschoal, T. (2013). Well-being at work scale: Exploratory and confirmatory validation in the United States comprising affective and cognitive components. XXXVII Encontro da ANPAD (pp. 1-16). Rio de Janeiro. 
Dessen, M. C. (2010). Indicadores de bem-estar pessoal nas organizações: O impacto da percepção da cultura, do perfil pessoal e das ações de qualidade de vida no trabalho e de qualidade de vida do trabalhador (Tese de doutorado). Recuperado de http://repositorio.unb.br/bitstream/10482/8326/1/2010_MarinaCamposDessen.pdf

Dessen, M. C., \& Paz, M. G. T. (2010). Validação do instrumento de indicadores de bem-estar pessoal nas organizações. Psicologia em Estudo, 15(2), 409-418. doi:10.1590/s1413-73722010000200020

Diener, E., \& Ryan, K. (2008). Subjetive well-being: A general overview. South African Journal of Psychology, 39(4), $391-406$. doi:10.1177/008124630903900402

Elfström, M. L., \& Kreuter, M. (2006). Relationships between locus of control, coping strategies and emotional well-being in persons with spinal cord lesion. Journal of Clinical Psychology in Medical Settings, 13(1), 89-100. doi:10.1007/s10880-005$9001-8$

Ferreira, M. C., Pacheco, S., Pinto, N. M., Fernandes, H. A., \& Silva, A. P. C. (2007). O bem-estar no trabalho e a predição de exaustão emocional. XXXI ENANPAD, (pp.1-9). Rio de Janeiro.

Ferreira, M. C., Souza, M. A., \& Silva, C. A. (2012). Qualidade de vida e bem-estar no trabalho: Principais tendências e perspectivas teóricas. In M. C. Ferreira \& H. Mendonça (Orgs.), Saúde e bem-estar no trabalho: Dimensões individuais e culturais (pp. 79-103). São Paulo: Casa do Psicólogo.

Field, A. (2009). Descobrindo a estatística usando o SPSS. Porto Alegre: Artmed.

García, M. F. M., Ramírez, M. G., \& Jariego, I. M. (2002). Social support and locus of control as predictors of psychological wellbeing in Moroccan and Peruvian immigrant women in Spain. International Journal of Intercultural Relations, 26(3), $287-310$. doi:10.1016/s0147-1767(02)00005-6

Giacomoni, C. H. (2004). Bem-estar subjetivo: Em busca da qualidade de vida. Temas em Psicologia da Sociedade Brasileira de Psicologia, 12(1), 43-50.

Guimarães, L. M. A., Stephanini, I. C., Barros, N. H. S., Mayer, V. M., Andrade, P. R., Soares, A. S., Hentschenke, M. R., Ribeiro, J. S., Achkar, T. C. S., \& Gomes, E. C. V. V. (2008). Locus de controle e trabalho. In L. A. M. Guimarães \& S. Grubits (Orgs.), Série saúde mental e trabalho, IV (Vol. IV, pp. 101-110). São Paulo: Casa do Psicólogo.

Mendes, A. M., \& Cruz, R. M. (2004). Trabalho e saúde no contexto organizacional: Vicissitudes teóricas. In A. Tamayo (Org.), Cultura e saúde nas organizações (pp. 39-55). Porto Alegre: Artmed.

Mohan, K. P. (2004). Work specific locus of control as a moderator of the relationship between organizational stressors and job related well-being (Tese de doutorado). Recuperado de http://bsris.swu.ac.th/thesis/452996006RB901.pdf

Ng, T. W. H., Sorensen, K. L., \& Eby, L. T. (2006). Locus of control at work: A meta-analysis. Journal of Organizational Behavior, 27(8), 1057-1087. doi:10.1002/job.416

Noriega, J. A. V., Albuquerque, F. J. B., Álvarez, J. F. L., Oliveira, L. M. S., \& Coronado, G. (2003). Locus de controle em uma população do nordeste brasileiro. Psicologia: Teoria e Pesquisa, 19(3), 211-220. doi:10.1590/s0102-37722003000300003

Paschoal, T. (2008). Bem-estar no trabalho: Relações com suporte organizacional, prioridades axiológicas e oportunidades de alcance de valores pessoais no trabalho (Tese de doutorado). Recuperado de http://repositorio.unb.br/handle/10482/5551

Paschoal, T., Demo, G., Fogaça, N., Ponte, V., Edrei, L., Francischeto, L., \& Albuquerque, G. (2013). Bem-estar no trabalho: Cenário dos estudos brasileiros publicados na primeira década do novo milênio. Special Issue, 2, 383-395

Pasquali, L., Alves, A. M., \& Pereira, M. A. M. (1998). Escala de locus de controle ELCO/Telebrás. Psicologia: Reflexão e Crítica, 11(2), 363-378. doi:10.1590/s0102-79721998000200013

Paz, M. G. T. (2004). Poder e saúde organizacional. In A. Tamayo (Org.), Cultura e saúde nas organizações (pp. 127-154). Porto Alegre: Artmed.

Paz, M. G. T., Gosendo, E. E. M., Dessen, M. C., \& Mourão, R. G. V. (2009). Justiça organizacional e bem-estar pessoal nas organizações. Estudos (Goiânia), 36(1/2), 95-115.

Paz, M. G. T., Neiva, E. R., \& Dessen, M. C. (2012). Bem-estar e felicidade nas organizações: Um só fenômeno? In M. C. Ferreira \& H. Mendonça (Orgs.), Saúde e bem-estar no trabalho: Dimensões individuais e culturais (pp. 105-130). São Paulo: Casa do Psicólogo.

Rodrigues, D. M. (2007). Os aspectos cognitivos da qualidade de vida: Um estudo entre as variáveis locus de controle e as do bem-estar subjetivo (Tese de doutorado não publicada). Universidade Federal do Rio de Janeiro, Rio de Janeiro.

Rodrigues, D. M., \& Pereira, C. A. A. (2007). A percepção de controle como fonte de bem-estar. Estudos e Pesquisas em Psicologia, 7(3), 541-556. 
Rodríguez-Carvajal, R., Moreno-Jiménez, B., Rivas-Hermosilla, S., Álvarez-Bejarano, A., \& Vergel, A. I. S. (2010). Positive psychology at work: Mutual gains for individuals and organizations. Revista de Psicología del Trabajo y de las Organizaciones, 26(3), 235-253. doi: 10.5093/tr2010v26n3a7

Rotter, J. B. (1966). Generalized expectancies for internal versus external control of reinforcement. Psychological Monographs: General and Applied, 80(1), 1-28. doi:10.1037/h0092976

Siqueira, M. M. M., \& Padovam, V. A. R. (2008). Bases teóricas de bem-estar subjetivo, bem-estar psicológico e bem-estar no trabalho. Psicologia: Teoria e Pesquisa, 24(2), 201-209. doi:10.1590/s0102-37722008000200010

Souza, R. R. (2012). Valores organizacionais como antecedentes de bem-estar nas organizações. Revista Negócios em Projeção, 3(1), 31-50.

Spector, P. E. (1988). Development of the work locus of control scale. Journal of Occupational Psychology, 61, 335-340. doi:10.1111/j.2044-8325.1988.tb00470.x

Spector, P. E., Cooper, C. L., Sanchez, J. I., O’Driscoll, M., \& Parks, K. (2002). Locus of control and well-being at work: How generalizable are western findings? Academy of Management Journal, 45(2), 453-466. doi:10.2307/3069359

Van Horn, J. E., Taris, T. W., Schaufeli, W. B., \& Schreurs, P. J. G. (2004). The structure of occupational wellbeing: A study among Dutch teachers. Journal of Occupational and Organizational Psychology, 77(3), 365-375. doi:10.1348/0963179041752718

Vasconcelos, A. F. (2004). Felicidade no ambiente de trabalho: Exame e proposição de algumas variáveis críticas. Revista Eletrônica de Administração, 10(1), 1-18.

Xavier, V. M. C. (2005). Locus de controle, comprometimento organizacional e satisfação no trabalho: Um estudo correlacional (Dissertação de mestrado). Recuperado de http://www.pgpsi.ip.ufu.br/node/271

Wang, Q., Bowling, N. A., \& Eschleman, K. J. (2010). A meta-analytic examination of work and general locus of control. The Journal of Applied Psychology, 95(4), 761-768. doi:10.1037/a0017707

Warr, P. (1978). A study of psychological well-being. British Journal of Psychology, 69, 111-121. doi:10.1111/j.2044-8295.1978. tb01638.x

Warr, P. (2007). Learning about employee happiness. Revista Psicologia Organizações e Trabalho, 7(2), 133-140. 